\title{
Prevalence of Stress Among Software Professionals in Hyderabad, Telangana State, India
}

\author{
Revathi Goud Vaskari ${ }^{1}$, Vinod Babu Sugumaran ${ }^{2, *}$ \\ ${ }^{1}$ Virinchi Hospitals Pvt. Ltd, Hyderabad, India \\ ${ }^{2}$ Department of Biochemistry, Mahatma Gandhi Medical College and Research Institute, Puducherry, India
}

Email address:

drvinodbabu@gmail.com (Vinod B. S.)

${ }^{*}$ Corresponding author

To cite this article:

Revathi Goud Vaskari, Vinod Babu Sugumaran. Prevalence of Stress Among Software Professionals in Hyderabad, Telangana State, India. Central African Journal of Public Health. Vol. 6, No. 4, 2020, pp. 207-212. doi: 10.11648/j.cajph.20200604.14

Received: April 26, 2020; Accepted: June 23, 2020; Published: July 6, 2020

\begin{abstract}
Background: In IT sector, factors leading to work stress and its impact on employee performance is an important factor. The factors leading to work stress and its impact on employee performance is vital for any organization to ensure its success and smooth functioning. Various studies have been done in the field of Information Technology, regarding the factors leading to work stress and its impact on employee performance. The Aim of this research mainly focuses to find out the relationship between job satisfaction of employees and how it contributes factors leading to work stress and its impact on employee performance from the target people working in an IT Company within the state of Telangana. This is a cross-sectional study involving employees from Information Technology Sector in Hyderabad, Telangana State, India. Using a structured and validated questionnaire, data were collected from 51 employees and the data was tabulated in proper format for further statistical analysis using Cronbach's alpha analysis was performed to assess the validity and reliability of the questionnaire. Using the stress score as a guideline as per ISMA questionnaire, the study participants were divided into 3 groups depending upon the severity of stress as mild, moderate and severe respectively. The goals of my thesis research were to identify the prevalence of stress among the participants in this study and also to segregate them into different groups of mild, moderate or severely stressed groups based with reference to International Stress Management Questionnaire (ISMA Questionnaire). The net result also shows that more than $50 \%$ of the study group is in group 2 where they are more prone for stress showing the impact of stress on working process. To conclude, Stress awareness programs to be conducted frequently in the office for all working professionals. As a professional every individual must have knowledge about how to overcome stress at every stage of his/her life.
\end{abstract}

Keywords: Job Stress, Software, Information Technology

\section{Introduction}

Work-related stress is one of the biggest health and safety challenges that the whole world faces [1]. Research has shown that stress has a negative impact on the health and also on the safety and mental well being of individuals [2, 3]. Costs associated with occupational stress in terms of loss of pay due to absenteeism, and expenses in hospitalization have significant implication in overall growth of any organization [4]. Stress has been examined in a wide variety of professional groups such as teachers, nurses, accountants, managers, and pilots. To date, little attention has been devoted to examining occupational stress among professionals and employees working in information technology sector. The limited research which exists on this topic so far is generally focused on IT personnel in the United States [5]. The paucity of research on stress among IT personnel is surprising with the evidences from popular business magazines as well as empirical evidence from research examining the changing roles of IT personnel [6]. Results of such research suggest that the role of IT personnel has become more complex and demanding, resulting in additional responsibilities for them in everyday of their work-life losing some balance in moving forward.

Rapid changes in technology and its use have also resulted in significant changes in expectations of users and managers [7]. Thus, we would expect such changes to pose additional challenges as well as generate considerable stress among IT 
personnel.

India is an ideal country in Asia to investigate stress among this group of professionals due to its heavy reliance on Information Technology to develop the country into a communication, business and economic centre for Asia.

Research shows that the many of the stressful type of work is that which demands excessive pressures that are not compatible to workers' knowledge and abilities, because there is no opportunity to practice any choice or control, and there is no support from others.

IT personnel represent a dynamic workforce in that sector for the future. Thus, it is important for managers and organizations to understand the different types of stressors experienced by the employees in that sector and also help out to assist them in managing stress better at the workplace. The factors leading to work stress and its impact on employee performance with special reference to IT sector is discussed in this study.

\section{Subjects and Methods}

This is a cross-sectional study involving employees from Information Technology Sector in Hyderabad, Telangana State, India.

As there were no such studies available with respect to this topic in this area, we have done a pilot study with 51 employees and collected data using a structured and validated questionnaire. The study was started after getting the consent from the participants. The employees, enrolled voluntarily to the study, and the inclusion and exclusion criteria were as follows.

Inclusion Criteria:

1. Should be working for at least 2 years in the industry.

2. Males and Females.

Exclusion criteria:

1. $<2$ years in Industry.

2. Any known Psychiatric illness.
The questionnaire was framed from previous research studies and the guidelines from International Stress Management Association were also followed. The questionnaire was validated sequentially and then only sent by mail as Google forms to the IT professionals with an informed consent.

Statistics:

The results obtained through the questionnaire were statistically analyzed using SPSS verison 15.0 and was checked for if there is any correlation using the $p$-value.

\section{Results}

51 responses were received. The results were incorporated in excel sheet and used for statistical analysis. The statistical analysis was done after converting the responses received as yes or no to 1 or 2 respectively.

Cronbach's alpha analysis (Table 1) was performed to assess the validity and reliability of the questionnaire [8]. Inter-item Correlation Matrix and ANOVA were performed to check for the statistical significance for differences in mean between the groups.

Using the stress score as a guideline as per ISMA questionnaire, the study participants were divided into 3 groups depending upon the severity of stress as mild, moderate and severe respectively. The results were presented in tabular form and also presented as bar charts.

Table 1 shows the Cronbach's alpha reliability statistics for showing the questionnaire to be valid and the value obtained was 0.709 .

Table 1. Cronbach's Alpha - Reliability Statistics.

\begin{tabular}{ll}
\hline Reliability Statistics & Value \\
\hline No. of Items & 16 \\
Cronbach's Alpha & 0.709 \\
\hline
\end{tabular}

Table 2. Responses of the Participants in Percentage.

\begin{tabular}{|c|c|c|c|}
\hline Q. No. & Questions & YES (\%) & NO $(\%)$ \\
\hline 1 & I do the jobs myself to ensure that they are done properly & $50(98)$ & $1(2)$ \\
\hline 2 & I feel that there are too many deadlines in my work/life that are difficult to meet & $32(62.7)$ & $19(37.3)$ \\
\hline 3 & I find myself thinking about problems even when I am supposed to be relaxing & $36(70.6)$ & $15(29.4)$ \\
\hline 4 & I deny or ignore problems in the hope that they are done properly & $21(41.2)$ & $38(58.8)$ \\
\hline 5 & I have tendency to eat, talk walk and drive quickly & $34(66.7)$ & $17(33.3)$ \\
\hline 6 & My appetite has changed, loss of appetite, skip meals & $19(37.3)$ & $32(62.7)$ \\
\hline 7 & When I play sports or games i really try to win whoever I play & $41(80.4)$ & $10(19.6)$ \\
\hline 9 & I find myself grinding my teeth & $13(25.5)$ & $38(74.5)$ \\
\hline 10 & Increase in muscular aches, pains, head, neck, lower back, shoulder & $20(39.2)$ & $31(60.8)$ \\
\hline 11 & I find I have greater dependency on alcohol, caffeine, nicotine, drugs & $8(15.7)$ & $43(84.3)$ \\
\hline 12 & I do meditation, work stress relief exercises regularly & $9(17.6)$ & $42(82.4)$ \\
\hline 13 & I don't feel to talk to others and being alone & $17(33.3)$ & $34(66.7)$ \\
\hline 14 & My health is affected due to stress which I carry from work & $21(41.2)$ & $38(58.8)$ \\
\hline 15 & I feel fatigued or tired even when I wake after adequate sleep of 6 to $8 \mathrm{hrs} /$ per day & $27(52.9)$ & $24(47.1)$ \\
\hline
\end{tabular}

Table 2 shows the responses of the participants in percentage for the questionnaire given. The frequency number is quoted and the percentage for the same was put in brackets.
Table 3 shows the groups when segregated based on stress score in the study group. Groups were divided into 1, 2 and 3 representing mild or no stress, moderate and severely stressed groups respectively. Here we got the score as $17.6 \%$, 
$56.9 \% \& 25.5 \%$ as mild, moderate and severely stressed participants in groups $1,2 \& 3$ respectively.

Table 3. Groups based on stress score in study group.

\begin{tabular}{lllll}
\hline Group & Frequency & Percent & Valid Percent & Cummulative Percent \\
\hline 1 & 9 & 17.6 & 17.6 & 17.6 \\
2 & 29 & 56.9 & 56.9 & 74.5 \\
3 & 13 & 25.5 & 25.5 & 100 \\
Total & 51 & 100 & 100 & \\
\hline
\end{tabular}

Group $1-4$ points or less: Least likely to suffer from stress-related illness.

Group $2-5-13$ points: More likely to experience stress related ill health either mental, physical or both. You would benefit from stress management counseling or advice to help in the identified areas.

Group $3-14$ points or more: Most prone to stress showing characteristics that are creating un-healthy behaviours.

Figure 1 shows the graph representing the responses of the participants in percentage (\%) with its $\mathrm{X}$-axis as Question number of the questionnaire and Y-Axis as total questions answered in percentage.

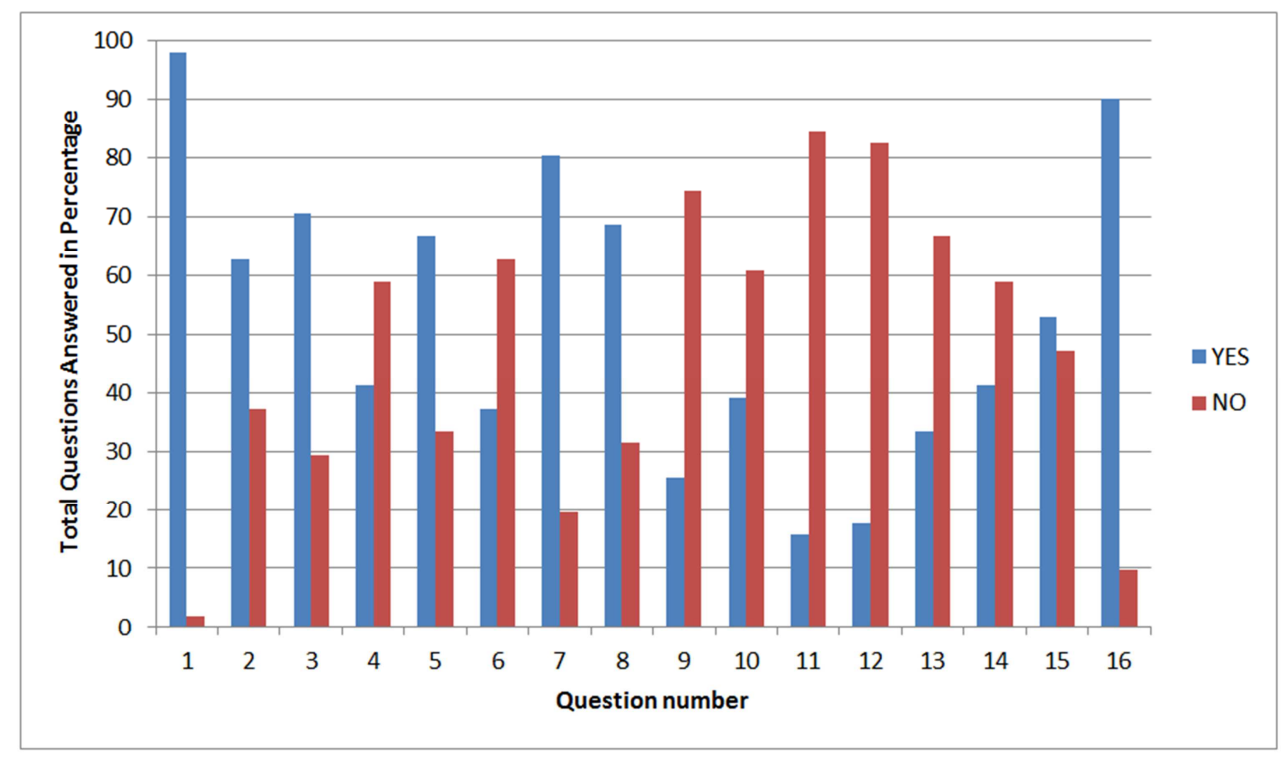

Figure 1. Graph representing the responses of the participants in percentage (\%).

Figure 2 shows pie chart representing the groups based on stress score in study group segregating the participants into people with no or mild stress (17.60\%), more likely to have stress $(56.90 \%)$ and most prone for stress $(25.50 \%)$ in groups 1,2 and 3 respectively.

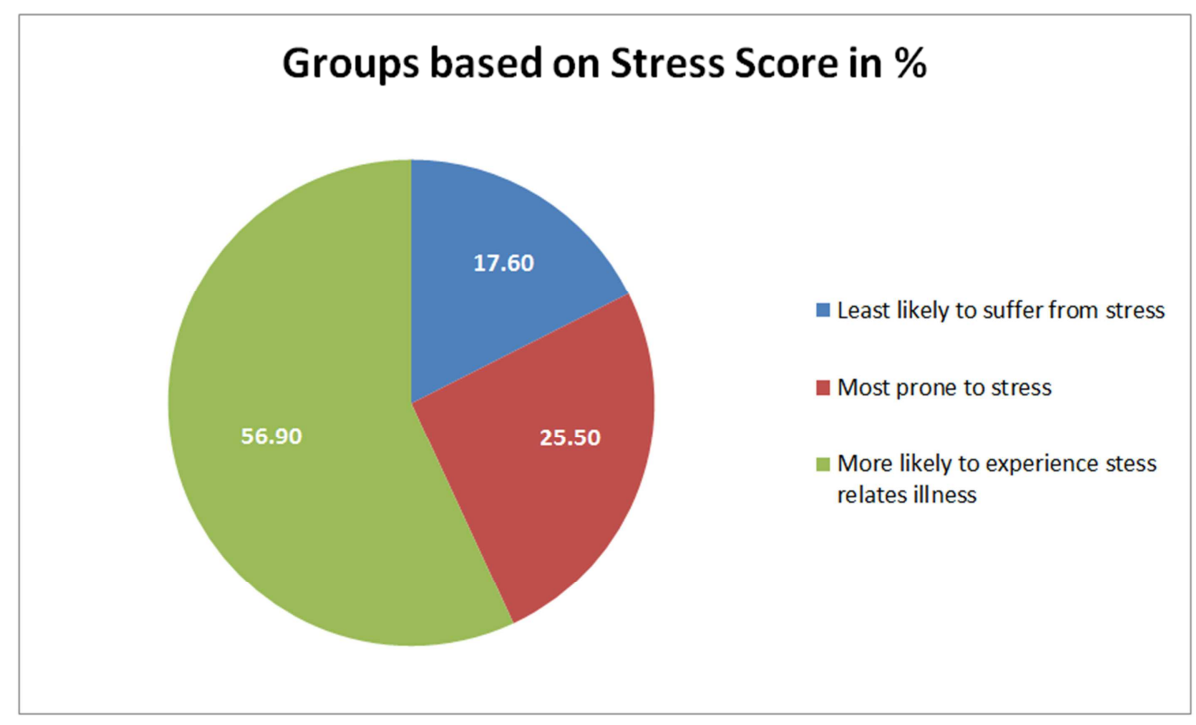

Figure 2. Graph representing the groups based on stress score in study group. 


\section{Discussion}

Studies have shown that employees with chronic work stress (three or more exposures) were nearly twice more likely to develop the metabolic syndrome than those with no exposure to work stress. Women with chronic work stress were over five times more likely to have the metabolic syndrome $[9,10]$.

Though this study had equal effect on both men and women, statistically there was no significant correlation obtained.

The results of our study, as shown in table 2 and figure 1, are instructive in that they seem to suggest that most of the factors which generate stress among IT personnel are linked to various characteristics of their work environment, particularly pressures associated with the job and its' organizational mandates to be followed. This study also shows that less number of personnel being concentrated on meditation and stress relieving activities which may also me a cause for $>50$ percent of participants in more prone to be stressed group.

As shown in table 3, it is evident that there is some amount of stress may be mild, moderate or severe type undergone by every individual working in software sector and in our study approximately 55 percent of study group are in moderate stress.

The question on use of gadgets in late night may be also a reason behind getting stress because of reduced sleeping hours and using gadgets at that time [11]. Approximately 90 percent of the participants have accepted the use of gadgets in night which needs a separate area for research and also add other biochemical analyte into research for use of gadgets in night.

The job work done personally by themselves or not is the place where we can find the confidentiality in the employees and the urge for them to work for the organization is known where $98 \%$ of participants have mentioned that they do all their job in the company by themselves and not depending on others. Here the Organization plays a major role where they must take care of their employees and give them a peaceful atmosphere to achieve their goal.

The impact of IT on our day to day activities continues to be unabated. As innovations in the field of technology increases, this influence will continue to grow in the coming years at an alarmingly increasing rate. This brings extra pressure on people to adapt to new advancements and update their knowledge in their respective fields. Annual stress scoring has to be done and a score above the reference value will definitely be in need of stress management program like yoga, meditation and other distressing activities like aerobics, dance etc., which would prevent or reduce risk of diseases due to stress in the professionals of Information Technology Sector, which in turn will produce a healthy community [12].

To manage stress these people need to get into the ground and play active sports, have a hobby or just have a good holiday or any weekend trips once in a month also will suffice [13].
Healthy employees, mean better performance by an employee, will in turn produce a healthy work atmosphere and therefore good results in the work they do. Annual stress scoring protocol should be maintained and people showing positive for high stress should be involved in active antistress management [12].

Technostress is the word used to explain the phenomenon of stress arising due to the usage of computers. It is a modern disease of adaptation caused by the inability to cope with new computer technologies in a healthy manner [14].

\section{Conclusion}

The goals of my thesis research were to identify the prevalence of stress among the participants in this study and also to segregate them into different groups of mild, moderate or severely stressed groups based with reference to International Stress Management Questionnaire (ISMA Qestionnaire). The net result also shows that more than 50\% of the study group is in group 2 where they are more prone for stress showing the impact of stress on working process and also to show the importance of Stress Management for working professionals is highly essential.

The Organization must acknowledge the need of solving, preventing and fighting with stress at work. The most effective methods of those actions will result in positive growth of the Organization. Only when one element is working correctly with another one, the outcome that is seen is enormous and efficient from all individuals of the Organization.

This study also shows that nowadays caring about the employees is never waste of money or time, and that only the specialists can help in critical situations. Moreover this research shows that the Stress Management could be a good push for developments and improvements in every individual of the Organization.

This research brightly shows that there is a great importance of such factors and ways to cope with stress as relaxation, comfortable atmosphere, analyzing the problem and healthy lifestyle to be followed. All research results creates good basis for company's future, telling about stress and Stress Management from every quarter and presenting the best pieces of advices of how to prevent, cope and fight with stress situations at work will bring about quality work from the employees in the Organization.

Stress has become a part of daily life for the every individual in this modern society. It changes our lifestyle according to the situations. That is why for the companies and employed people, who care about the work efficiency and their own well-being, my research will be meaningful. The effort which is needed to accomplish the huge task in order to prevent stress and its interventions seems to be enormous and waste of time but it's not so actually.

Organizations started thinking about the well-being of employees at work place relatively not long ago, as well as Stress Management was developed in recent years only. Therefore the research is quite modern and is the need of the 
hour. Moreover some of the results are really unexpected and seems to be new, and the results which coincide with previous research results prove their reliability. However, in the current moment, there are only a few researches on the topic of Stress at work.

Among some of the major problems experienced by the IT industry in recent years are difficulties in recruitment and increasing volume of turnover among IT personnel. Shortage and turnover remain a pressing problem that organizations have to deal with. IT professionals usually leave their jobs for better career advancement, more lucrative pay and better personal growth and development.

Steps should be taken to assist these employees, especially the women in their professional development and career advancements as well as help them better to coordinate their family and office work responsibilities perfectly.

In my opinion the research is not only useful for the companies, but also presents the ideas for establishing newer references and areas to be concerned upon. Such issues like prevention, reduction and fighting with stress can be studied deeper separately and presented as individual researches.

\subsection{Recommendations}

1. Time Management to complete projects within the given time span [15] and identify methods to overcome stress and to plan and execute the ideas.

2. Stress awareness programs to be conducted frequently in the office for all working professionals [16].

3. Week-end outings, relaxing games and refreshments in between work are in high need for professionals which must be used appropriately by them without causing any issues or break in their work.

4. To overcome addictions like caffeine, smoking and drinking and also drug abuse if any. De-addiction must be motivated by presenting awards [17].

5. Sleeping pattern including time to sleep, total no. of hours to sleep (6-8 hrs) and also to avoid gadgets at time of sleep must be thoughtfully provoked and its essentials and wellness in health must be stressed upon for the professionals [18].

6. Health education and awareness program to be conducted for employees at regular intervals [19].

\subsection{Newer Strategies}

1. The Company must give options for the professionals to participate in laughter clubs and meditation centres to be relieved from stress.

2. Having a female mentor to turn to, in times of need and who can provide feedback and advice may increase the confidence of female IT personnel and help them deal with stress better.

\section{Acknowledgements}

We would like to acknowledge the faculty of Indian Institute of Public Health, Gandhinagar, Dr. Shyam Pingle,
Sr. Occupational Health Specialist \& Adjunct Professor and Dr. Mayur Trivedi, Associate Professor for their constant support and guidance throughout this research.

\section{References}

[1] Vourvachis P, Kladi K. Accounting for stress: a comparative analysis of corporate reporting on work-related stress by UK, German and Greek companies. 2013 Mar 18 [cited 2020 Jun 20]; Available from: https://ore.exeter.ac.uk/repository/handle/10036/4488.

[2] Rees DW. Work-related stress in health service employees. J Manag Psychol. 1995 Mar 1; 10 (3): 4-11.

[3] Westman M, Eden D. Effects of a respite from work on burnout: Vacation relief and fade-out. J Appl Psychol [Internet]. [cited 2020 Jun 19]; Available from: https://www.academia.edu/21119415/Effects_of_a_respite_fr om_work_on_burnout_Vacation_relief_and_fade-out.

[4] (PDF) The cost of work-related stress: a systematic review [Internet]. [cited 2020 Jun 20]. Available from: https://www.researchgate.net/publication/313480340_The_cos t_of_work-related_stress_a_systematic_review.

[5] Weiss M. Effects of Work Stress and Social Support on Information Systems Managers. MIS Q. 1983; 7 (1): 29-43.

[6] How Technology Is Changing Work and Organizations [Internet]. [cited 2020 Jun 21]. Available from: https://www.researchgate.net/publication/299400943_How_T echnology_Is_Changing_Work_and_Organizations.

[7] Lim VKG, Teo TSH. Occupational stress and IT personnel in Singapore: Factorial dimensions and differential effects. In: in International Journal of Information Management; 19. 1999. p. 277-291.

[8] Bolarinwa. Principles and methods of validity and reliability testing of questionnaires used in social and health science researches [Internet]. [cited 2020 Jun 19]. Available from: http://www.npmj.org/article.asp?issn=1117-

1936; year $=2015$; volume $=22$; issue $=4$; page $=195$; epage $=201$; ulast=Bolarinwa.

[9] Chandola T, Brunner E, Marmot M. Chronic stress at work and the metabolic syndrome: prospective study. BMJ. 2006 Mar 4; 332 (7540): 521-5.

[10] Shift work and metabolic syndrome: A multi-center crosssectional study on females of reproductive age [Internet]. [cited 2020 Jun 20]. Available from: https://www.spandidospublications.com/10.3892/br.2019.1205.

[11] Thomée S, Härenstam A, Hagberg M. Mobile phone use and stress, sleep disturbances, and symptoms of depression among young adults - a prospective cohort study. BMC Public Health. 2011 Jan 31; 11: 66.

[12] Padma V, Anand NN, Gurukul SMGS, Javid SMASM, Prasad A, Arun S. Health problems and stress in Information Technology and Business Process Outsourcing employees. J Pharm Bioallied Sci. 2015 Apr; 7 (Suppl 1): S9-13.

[13] Stults-Kolehmainen MA, Sinha R. The Effects of Stress on Physical Activity and Exercise. Sports Med Auckl NZ. 2014 Jan; 44 (1): 81-121. 
[14] Brivio E, Gaudioso F, Vergine I, Mirizzi CR, Reina C, Stellari A, et al. Preventing Technostress Through Positive Technology. Front Psychol [Internet]. 2018 Dec 17 [cited 2020 Jun 19]; 9. Available from: https://www.ncbi.nlm.nih.gov/pmc/articles/PMC6304421/.

[15] Kemna E, Pickkers P, Nemeth E, van der Hoeven H, Swinkels D. Time-course analysis of hepcidin, serum iron, and plasma cytokine levels in humans injected with LPS. Blood. 2005 Sep $1 ; 106$ (5): 1864-6.

[16] Bhui K, Dinos S, Galant-Miecznikowska M, de Jongh B, Stansfeld S. Perceptions of work stress causes and effective interventions in employees working in public, private and non-governmental organisations: a qualitative study. BJPsych Bull. 2016 Dec; 40 (6): 318-25.
[17] Chronic Stress, Drug Use, and Vulnerability to Addiction [Internet]. [cited 2020 Jun 20]. Available from: https://www.ncbi.nlm.nih.gov/pmc/articles/PMC2732004/.

[18] Kim E-J, Dimsdale JE. The Effect of Psychosocial Stress on Sleep: A Review of Polysomnographic Evidence. Behav Sleep Med. 2007; 5 (4): 256-78.

[19] Abraham J, Feldman R, Carlin C. Understanding Employee Awareness of Health Care Quality Information: How Can Employers Benefit? Health Serv Res. 2004 Dec; 39 (6 Pt 1): 1799-816. 